\title{
Increased CD36 protein as a response to defective insulin signaling in macrophages
}

\author{
Chien-Ping Liang, Seongah Han, Haruka Okamoto, Ronald Carnemolla, Ira Tabas, \\ Domenico Accili, and Alan R. Tall
}

Divisions of Molecular Medicine and Endocrinology, Department of Medicine, Columbia University, New York, New York, USA.

\begin{abstract}
Accelerated atherosclerosis is a major cause of morbidity and death in insulin-resistant states such as obesity and the metabolic syndrome, but the underlying mechanisms are poorly understood. We show that macrophages from obese $(o b / o b)$ mice have increased binding and uptake of oxidized LDL, in part due to a posttranscriptional increase in CD36 protein. Macrophages from $o b / o b$ mice are also insulin resistant, as shown by reduced expression and signaling of insulin receptors. Three lines of evidence indicate that the increase in CD36 is caused by defective insulin signaling: (a) Treatment of wild-type macrophages with LY294002, an inhibitor of insulin signaling via PI3K, results in an increase in CD36; (b) insulin receptor knockout macrophages show a post-transcriptional increase in CD36 protein; and (c) administration of thiazolidinediones to intact $o b / o b$ mice and $o b / o b$, LDL receptor-deficient mice results in a reversal of macrophage insulin receptor defects and decreases CD36 protein. The last finding contrasts with the increase in CD36 that results from treatment of macrophages with these drugs ex vivo. The results suggest that defective macrophage insulin signaling predisposes to foam cell formation and atherosclerosis in insulin-resistant states and that this is reversed in vivo by treatment with PPAR- $\gamma$ activators.
\end{abstract}

\section{Introduction}

The complications of atherosclerosis in coronary, cerebral, and peripheral arteries are the major reason for hospital admission in diabetics and account for about $80 \%$ of the mortality of this condition (1). Although diabetes is often associated with dyslipidemia (2, 3 ), the excess risk is disproportionate to lipid abnormalities and the root causes of accelerated atherosclerosis in diabetes are not well understood. Some evidence suggests that insulin resistance, commonly seen in overweight individuals with the metabolic syndrome, is an important cause of both diabetes and increased atherosclerosis risk (4). Insulin resistance has been related to dyslipidemia, hypertension, and hypercoagulability, all factors that may promote atherosclerosis $(2,3)$. Potentially insulin resistance could also be important at the arterial cellular level (5). Defective insulin signaling in endothelial cells leads to impaired NO activity (6), and this is probably proatherogenic. Macrophages also express insulin receptors (IRs) (7), but the relationship of insulin signaling to macrophage foam cell formation has received little attention.

Thiazolidinediones, activators of PPAR- $\gamma$, have emerged as an important class of drugs in the treatment of type II diabetes. PPAR$\gamma$ activators markedly improve insulin resistance and decrease atherosclerosis in mouse models, and may also decrease atherosclerosis in humans (8-11). Although the in vivo mode of action of PPAR- $\gamma$ activators is not well understood, PPAR- $\gamma$ is highly expressed in adipocytes and macrophages (11), suggesting these cells could be important targets. Paradoxically, however, PPAR- $\gamma$ activators increase the expression of the proatherogenic molecule CD36 in cultured macrophages (12). These proatherogenic effects of PPAR- $\gamma$ activators may be counteracted by an increase in ABCA1, a

Nonstandard abbreviations used: acetylated LDL (acLDL); insulin receptor (IR); IR substrate 2 (IRS-2); LDL receptor (LDLR); oxidized LDL (oxLDL); scavenger receptor A (SR-A); scavenger receptor BI (SR-BI); Tricine-buffered saline (TBS).

Conflict of interest: The authors have declared that no conflict of interest exists.

Citation for this article: J. Clin. Invest. 113:764-773 (2004). doi:10.1172/JCI200419528. macrophage transporter that promotes efflux of cholesterol to lipid-poor apolipoproteins, perhaps offsetting increased uptake of modified low-density lipoprotein (LDL) via CD36 $(11,13,14)$. However, the importance of this mechanism is uncertain, and some studies have failed to find any effect of PPAR- $\gamma$ activators on ABCA1 levels or lipid efflux in macrophages $(15,16)$.

Obese $(o b / o b)$ mice are genetically deficient in leptin and have been widely used as a model of insulin resistance and diabetes (17). In this study, we made the initial observation that macrophages from $o b / o b$ mice have increased uptake of modified LDL, due to post-transcriptional upregulation of CD36 protein. Unexpectedly, the increase in CD36 is caused by defective insulin signaling in macrophages, suggesting that macrophage insulin resistance promotes foam cell formation. Consistent with this hypothesis, in vivo treatment with PPAR- $\boldsymbol{\gamma}$ activators improved insulin resistance and decreased macrophage CD36 protein and uptake of oxidized LDL (oxLDL).

\section{Methods}

Animals. Obese $o b / o b$ and $l e a n^{+/+}$, and $o b /+$ and LDL receptor-deficient $\left(L D L R^{--}\right)$on a $\mathrm{C} 57 \mathrm{BL} / 6 \mathrm{~J}$ background were obtained from the Jackson Laboratory (Bar Harbor, Maine, USA). Mice deficient in both leptin and LDLR (ob/ob $\left.L D L R^{-/-}\right)$were generated by crossing of $o b /+$ and $L D L R^{-/-}$mice as described (18). All experiments were performed with animals fed regular rodent chow diet, except that in the experiments of in vivo rosiglitazone treatment, ob/ob $L D L R^{-/-}$and $L D L R^{-/}$mice were fed a Western-type diet (TD88137; HarlanTeklad, Madison, Wisconsin, USA). At least three mice of each group were used in the experiments of this study. All experimental procedures were carried out in accordance with Columbia University's institutional guidelines for use of laboratory animals.

Macrophage and monocyte isolation. Thioglycollate-elicited peritoneal macrophages from at least three $o b / o b$ and $l e a n^{+/+}$mice or from transgenically rescued IR KO mice and littermate mice $(19,20)$ were collected by peritoneal lavage, and pooled macrophages of each strain were cultured as described (21), except that $0.2 \%$ bovine serum 
albumin (BSA) was supplemented in DMEM (Invitrogen, Carlsbad, California, USA) containing $1,000 \mathrm{mg} / \mathrm{l}$ of D-glucose unless otherwise specified. After 1-2 hours, the cells were washed three times with $1 \times$ phosphate-buffered saline (PBS; Invitrogen) and were used immediately for experiments as described below. For the isolation of mouse peripheral blood monocytes, the flotation method (22) with OptiPrep density gradient medium (Sigma-Aldrich, St. Louis, Missouri, USA) was used. Blood from lean $n^{+/+}$and $o b / o b$ mice was collected and mixed well with OptiPrep in Tricine-buffered saline (TBS; $0.85 \% \mathrm{NaCl}$ and $10 \mathrm{mM}$ Tricine- $\mathrm{NaOH}, \mathrm{pH}$ 7.4). The pooled samples were centrifuged at $1,000 \mathrm{~g}$ for 30 minutes at room temperature. The cells were harvested from the meniscus downwards and diluted into TBS. After being spun at $400 \mathrm{~g}$ for 10 minutes, the cells were resuspended and cultured as described above.

Acetylated $L D L(a c L D L)$ uptake and cholesteryl ester formation. We prepared acLDL and labeled it with ${ }^{125} \mathrm{I}$ and ${ }^{3} \mathrm{H}$ as described $(21,23)$. The assays of cell association, degradation, and cholesteryl ester formation with macrophages following loading of $\left[{ }^{125} \mathrm{I},{ }^{3} \mathrm{H}\right] \mathrm{acLDL}$ were performed as previously described $(23,24)$.

Binding assay for oxLDL. ${ }^{125}$ I-labeled oxLDL was prepared as described (25). Labeled oxLDL $(10-25 \mu \mathrm{g} / \mathrm{ml}$ or in amounts as indicated in Figure $1 \mathrm{E})$ in DMEM/0.2\% BSA with or without the addition of unlabeled oxLDL (40-fold excess; for estimates of nonspecific binding) were incubated for $2-3$ hours at $4^{\circ} \mathrm{C}$ with macrophages with or without prior treatments as indicated in figure legends. In some experiments, macrophages were preincubated for 30 minutes at $4{ }^{\circ} \mathrm{C}$ with fucoidan (Sigma-Aldrich), mouse anti-CD36 IgA (Cascade BioScience, Winchester, Massachusetts, USA), or control mouse IgA (Biodesign, Saco, Maine, USA) in DMEM/0.2\% BSA prior to the addition of oxLDL. After cells were washed on ice three times with ice-cold PBS, cell-associated ${ }^{125}$ I radioactivity was determined as described above.

Ex vivo treatments of macrophages and monocytes. Fresh peritoneal macrophages or blood monocytes were treated at $37^{\circ} \mathrm{C}$ in $\mathrm{DMEM} / 0.2 \%$ BSA with insulin (Sigma-Aldrich), wortmannin (Sigma-Aldrich), LY294002 (Biomol, Plymouth Meeting, Pennsylvania, USA), TNF- $\alpha$ (Sigma-Aldrich), oleic acid- or palmitic acid-BSA, rosiglitazone (GlaxoSmithKline, Research Triangle Park, North Carolina, USA), troglitazone (Parke-Davis, Morris Plains, New Jersey, USA), calpeptin (Calbiochem, La Jolla, California, USA), chloroquine (Sigma-Aldrich), lactacystin (Sigma-Aldrich), or corresponding vehicle controls for 1 day, unless otherwise specified; or in DMEM/10\% FBS for 1-2 days; or in glucose-free DMEM/0.2\% BSA with the indicated concentrations of glucose or mannitol (SigmaAldrich) for 1-2 days. Fresh wortmannin was added every 4-8 hours. Complexes of oleic acid or palmitic acid (Sigma-Aldrich) with BSA were prepared as described (26). After treatments, oxLDL binding assays were carried out, or total RNA and cell lysates were prepared for further analysis.

Pulse-chase labeling of macrophages. Peritoneal macrophages were incubated with methionine- and cysteine-free DMEM/0.2\% BSA for 1.5 hours at $37^{\circ} \mathrm{C}$. The cells were then incubated with Pro-Mix ${ }^{35} \mathrm{~S}$ celllabeling mix (0.2 mCi/ml; Amersham, Piscataway, New Jersey, USA) for 20 minutes or 4 hours at $37^{\circ} \mathrm{C}$ in methionine- and cysteine-free $\mathrm{DMEM} / 0.2 \% \mathrm{BSA}$, followed by washing of cells three times with PBS. Labeled macrophages were chased for the indicated times at $37^{\circ} \mathrm{C}$ in DMEM/0.2\% BSA. Subsequently, cells were rinsed three times with PBS and total cell lysates were prepared as described (21) with a lysis buffer (50 mM HEPES, $150 \mathrm{mM} \mathrm{NaCl}, 1.5 \mathrm{mM} \mathrm{MgCl}_{2}, 2.5 \mathrm{mM}$ EDTA, $1 \%$ Triton X-100, and $0.1 \%$ sodium deoxycholate, $\mathrm{pH} 7.4$ ) with protease inhibitor cocktail (Roche, Indianapolis, Indiana, USA).
Equal amounts $(100 \mu \mathrm{g})$ of total lysates were then used to immunoprecipitate ${ }^{35}$ S-labeled CD36 with mouse anti-CD36 IgA $(1 \mu \mathrm{g})$ overnight at $4^{\circ} \mathrm{C}$. Protein L-Agarose $(30 \mu \mathrm{l}$; Santa Cruz Biotechnology, Santa Cruz, California, USA) was added, followed by incubation for another 3 hours at $4^{\circ} \mathrm{C}$. After centrifugation agarose beads were washed four times with ice-cold lysis buffer without $0.1 \%$ sodium deoxycholate. Precipitated proteins were eluted from beads, separated by SDS-polyacrylamide gel electrophoresis (PAGE), electrotransferred to nitrocellulose membrane (Bio-Rad, Hercules, California, USA), and analyzed by autoradiography. The intensities of ${ }^{35} \mathrm{~S}$-labeled CD36 were quantified by densitometric analysis (Molecular Dynamics, Piscataway, New Jersey, USA).

Internalization assay. CD36 internalization in macrophages was assessed with reversible surface protein biotinylation as described (27). Fresh macrophages were incubated with sulfo-NHS-SS-biotin $\left(0.5 \mathrm{mg} / \mathrm{ml}\right.$; Pierce) for 40 minutes at $4^{\circ} \mathrm{C}$ in PBS with $1 \mathrm{mM} \mathrm{MgCl} 2$ and $0.5 \mathrm{mM} \mathrm{CaCl}_{2}$. Cells were washed three times with PBS and were then cultured in DMEM/0.2\% BSA for the indicated times at $37^{\circ} \mathrm{C}$, followed by surface biotin removal with or without glutathione (150 $\mathrm{mM}$; Sigma-Aldrich) twice for 20 minutes at $4^{\circ} \mathrm{C}$. After neutralization with iodoacetamide (50 mM; Sigma-Aldrich), macrophages were lysed with a lysis buffer and CD36 was immunoprecipitated as described above. After SDS-PAGE and membrane transfer, biotinylated CD36 was detected with streptavidin-HRP conjugate (Pierce) and quantified by densitometric analysis. Percent internalization was calculated as described (27) after the intensity of the CD36 band was corrected for input with $\beta$-actin.

Insulin-dependent tyrosine-phosphorylation assay. After 5 hours of serum starvation, macrophages were labeled with ${ }^{32} \mathrm{P}(0.2 \mathrm{mCi} / \mathrm{ml}$; Parkin-Elmer, Boston, Massachusetts, USA) for 2.5 hours at $37^{\circ} \mathrm{C}$ in $\mathrm{DMEM} / 0.2 \% \mathrm{BSA}$ then treated with insulin at the indicated concentrations at $37^{\circ} \mathrm{C}$. After 10 minutes, cells were frozen by liquid nitrogen to rapidly quench any further phosphorylation. Total cell lysates were prepared as described above with the addition of phosphatase inhibitor cocktail (Sigma-Aldrich), and $100-\mu \mathrm{g}$ samples were used to immunoprecipitate IRs with anti-IR IgG (Oncogene, Boston, Massachusetts, USA) or tyrosine-phosphorylated proteins with anti-phosphotyrosine IgG agarose (Santa Cruz Biotechnology). Immunoprecipitated IRs or phosphoproteins were separated by SDS-PAGE and transferred to nitrocellulose membrane. Insulindependent tyrosine-phosphorylated proteins were identified by autoradiography and Western analysis (see below). For the detection of tyrosine-phosphorylated IR or IR substrate 2 (IRS-2), the membranes were probed with anti-phosphotyrosine-HRP conjugate (Santa Cruz Biotechnology) or anti-IRS-2 (Upstate Biotechnology, Lake Placid, New York, USA), respectively.

In vivo treatment of mice with rosiglitazone. Obese $o b / o b$ mice were injected intraperitoneally once daily with rosiglitazone $(5 \mu \mathrm{g} / \mathrm{g}$ body weight) or PBS (saline control) for 17 days. For $L D L R^{-/-}$and $o b / o b$ $L D L R^{-1-}$ mice, animals were fed 4-5 g Western diet per mouse with or without rosiglitazone supplementation ( $3 \mu \mathrm{g} / \mathrm{g}$ body weight) each day for 3 weeks. At different times, blood was collected and blood glucose and insulin levels were measured with kits from SigmaAldrich and Crystal Chem Inc. (Chicago, Illinois, USA), respectively. Peritoneal macrophages from treated and control mice pre-elicited with thioglycollate were then obtained as described above and were used immediately for oxLDL binding assay or for preparation of RNA and total cell lysates.

Western analysis. Western analysis using total lysates $(25-50 \mu \mathrm{g})$ from macrophages, monocytes, or liver was performed as described 
(21) except that primary antibodies against CD36 (Santa Cruz Biotechnology and Cascade BioScience), scavenger receptor-A (SR-A) (TransGenic Inc., Kumamoto, Japan), scavenger receptor BI (SR-BI) (Novus Biologicals, Littleton, Colorado, USA), IR $\beta$-subunit (Santa Cruz Biotechnology), IRS-2 (Upstate Biotechnology), phosphotyrosine (Santa Cruz Biotechnology), or $\beta$-actin (Sigma-Aldrich) were used. Adipose tissue was homogenized in the lysis buffer described above and clarified lysates were prepared as described (21).

Northern analysis. Northern analysis using total RNA $(5-20 \mu \mathrm{g})$ isolated from peritoneal macrophages was carried out as described (28). The membranes were hybridized with randomly primed ${ }^{32} \mathrm{P}$-labeled probes of mouse CD36, SR-A, or $\beta$-actin cDNA fragments.

Real-time quantitative PCR analysis. Total RNA was reverse transcribed at $42^{\circ} \mathrm{C}$ with Superscript II (Life Technologies). For CD36 and $\beta$-actin mRNA measurements, $c D N A$ was mixed with TaqMan Universal PCR Master Mix (Perkin-Elmer Biosystems) according to the manufacturer's protocol. The following primers were used: CD36, 5'-FAM-TCACCCCTCCAGAATCCAGACAACCA-BHQ-1-3', forward, 5'-TCCAGCCAATGCCTTTGC-3', and reverse, 5'-TGGAGATTACTTTTTCAGTGCAGAA-3' (FAM, 6-carboxy-fluorescein; BHQ-1, Black Hole Quencher-1); $\beta$-actin, 5'-JOE-CACTGCCGCATCCTCTTCCTCCC-BHQ-1 3', forward, 5'-AGAGGGAAATCGTGCGTGAC-3', and reverse, 5'-CAATAGTGATGACCTGGCCGT-3' (JOE reporter dye from Molecular Probes, Invitrogen; primers synthesized by Biosearch Technologies Inc., Novato, California, USA). Detection of specific PCR products was performed in triplicate using the Mx4000 Multiplex Quantitative PCR System (Stratagene) with 1 cycle at $50^{\circ} \mathrm{C}$ for 2 minute and 1 cycle at $95^{\circ} \mathrm{C}$ for 10 minutes

\section{Figure 1}

Enhanced uptake of modified LDL in ob/ob versus WT mouse peritoneal macrophages is mediated by increases in cell surface expression of CD36 and SR-A. (A-C) $\left[{ }^{125},{ }^{3} \mathrm{H}\right]$ acLDL cell association (A), degradation (B), and cholesteryl ester formation (C) are higher in ob/ob than in WT macrophages following acLDL loading. One representative experiment of three independent experiments each using pooled macrophages from five WT and seven ob/ob mice is shown. Short-term treatment (5 hours) of macrophages with either insulin or leptin does not change these parameters. C $\rightarrow$ CE (vertical axis, C), cholesterol to cholesteryl ester. (D) Protein expression of scavenger receptors CD36 and SR-A is increased while SR-BI expression is decreased in ob/ob versus WT macrophages, as determined by Western analysis (left). Protein extracts were prepared from pooled macrophages of five WT and five ob/ob mice. One experiment representative of four independent experiments is shown. CD36 and SR-A mRNA was not upregulated in ob/ob versus WT macrophages, as shown by Northern analysis (right). Northern analysis was performed with random-primed CD36, SR-A, and actin CDNA probes using total RNA isolated from pooled macrophages of ten mice of each strain. One experiment representative of three independent experiments is shown. (E) Specific binding of oxLDL to $o b / o b$ macrophages is elevated. (F) Effects of fucoidan and anti-CD36 antibody on oxLDL binding to ob/ob and WT macrophages. [125I]oxLDL binding assays were performed with pooled macrophages isolated from five mice of each strain, preincubated with the SR-A ligand fucoidan $(20 \mu \mathrm{g} / \mathrm{ml})$, mouse anti-CD36 lgA $(20 \mu \mathrm{g} / \mathrm{ml})$, or mouse control $\operatorname{lgA}(20 \mu \mathrm{g} / \mathrm{ml}$, not shown). The decreases in total oxLDL binding in the presence of CD36 $\operatorname{IgA}$ or fucoidan were considered as binding mediated by CD36 or SR-A, respectively. CD36 contributes more to the increase in oxLDL binding to $o b / o b$ versus WT macrophages than SR-A. One experiment representative of three independent experiments is shown. CD36-depend. and SR-A depend., oxLDL binding mediated by CD36 and SR-A, respectively. followed by 45 cycles at $95^{\circ} \mathrm{C}$ for 15 seconds and $60^{\circ} \mathrm{C}$ for 1 minute. For the determination of mRNA levels of other genes, SYBR Green PCR Core Reagents (Perkin-Elmer Biosystems) were used as described by the manufacturer. Quantitative PCR was performed in triplicate using the Mx4000 Multiplex Quantitative PCR System with 1 cycle at $95^{\circ} \mathrm{C}$ for 10 minutes followed by 40 cycles of $90^{\circ} \mathrm{C}$ for 30 seconds, $58^{\circ} \mathrm{C}$ for 30 seconds and $72^{\circ} \mathrm{C}$ for 1 minute. The relative amounts of specific target amplicons for each primer set were estimated by a standard curve method using Mx4000 software (v.3.01; Stratagene) and were normalized to the copy number of mouse $\beta$-actin transcripts.

Statistical analysis. Results are expressed as means \pm SE.

\section{Results}

Increased uptake of modified LDL in ob/ob macrophages associated with increased levels of CD36 and SR-A. We compared the binding and uptake of LDL modified by acetylation or oxidation in pooled primary macrophages from $o b / o b$ and wild-type mice immediately after removing the macrophages from the peritoneal cavity. Using acLDL, there was two- to threefold increased cell association (Figure 1A), degradation (Figure 1B), and cholesteryl ester formation (Figure 1C) in $o b / o b$ macrophages compared with wild-type macrophages. A number of different macrophage receptors recognize acLDL, including CD36, SR-A, and SR-BI. Western blotting with specific antibodies against each of these receptors revealed increases in CD36 (2.5 \pm 0.4 -fold) and SR-A protein $(2.4 \pm 0.3$-fold), but reduced levels of SR-BI $(0.6 \pm 0.1)$ (Figure 1D). Measurements of mRNA by Northern analysis showed no increase in the mRNA of either SR-A or CD36 (0.8 \pm 0.2$)$ (Figure
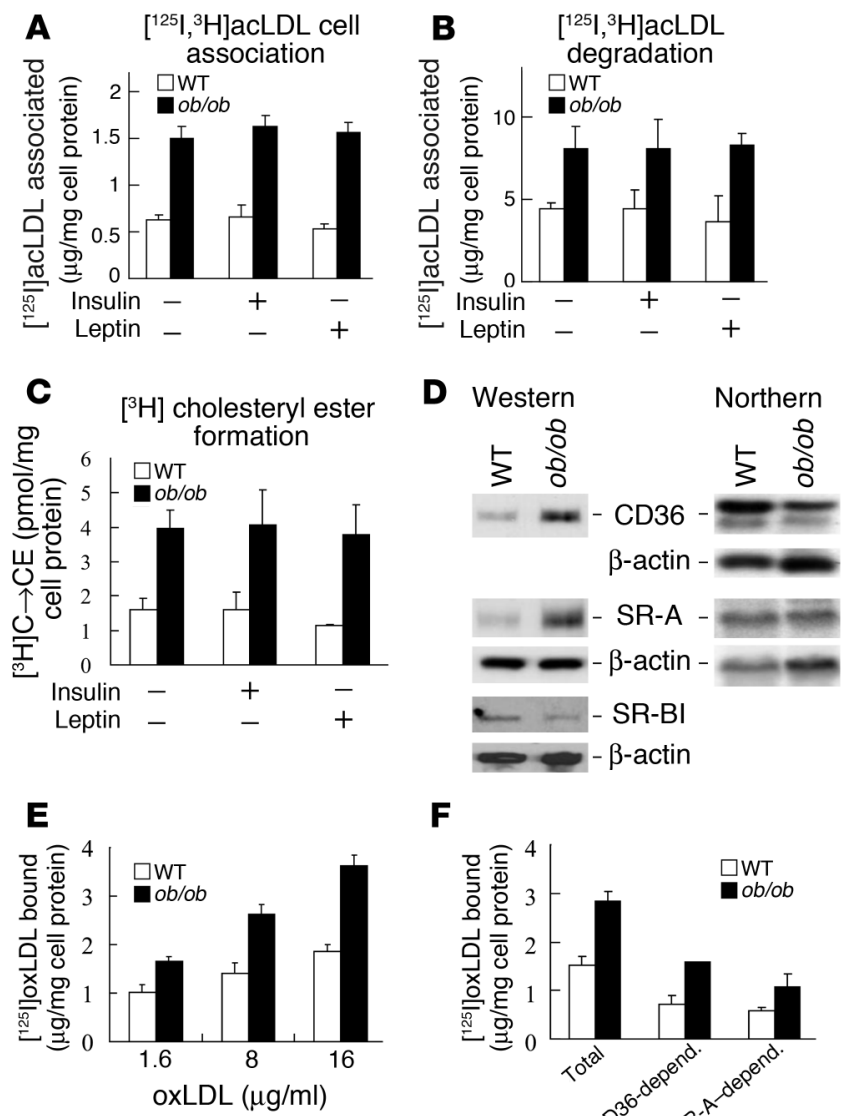

$\mathbf{F}$

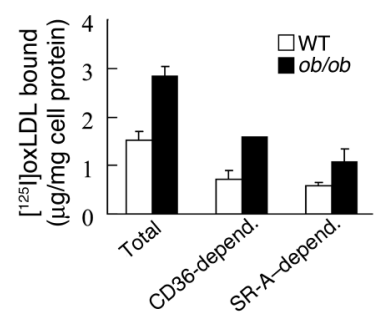


A

A 20 min pulse labeling
WT $\alpha$ CD36

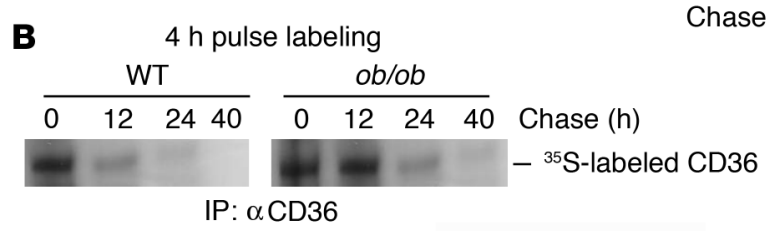

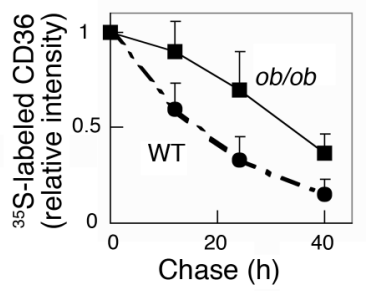

1D), indicating that the increase in protein was post-transcriptional. Macrophages from $o b / o b$ mice also showed increased binding of oxLDL (Figure 1E), consistent with increased levels of SR-A and CD36. To assess the relative importance of SR-A and CD36 in binding of oxLDL, macrophages were incubated with fucoidan, an inhibitor of SR-Adependent uptake (29), or with CD36 monoclonal antibodies (24, 25). Figure $1 \mathrm{~F}$ shows that binding attributable to both CD36 and SR-A was increased two- to threefold in $o b / o b$ versus wild-type mice, with the larger effect due to CD36. Control isotypematched antibodies did not reduce binding of oxLDL (data not shown). These studies reveal an increase in binding, uptake, and degradation of modified LDL in $o b / o b$ macrophages, primarily reflecting a post-transcriptional increase in CD36 protein.

Increased cholesteryl ester formation (Figure 1C) indicates a propensity for foam cell formation in $o b / o b$ macrophages and could reflect both increased uptake of modified LDL and potentially decreased cholesterol efflux. However, despite the reduced levels of SR-BI, cholesterol efflux to apoA-I or HDL was similar in $o b / o b$ and wild-type macrophages (data not shown), suggesting no significant defect in efflux. Thus, the major focus of subsequent studies was to elucidate the mechanism of the post-transcriptional increase in CD36 protein in $o b / o b$ macrophages.

Increased CD36 results from decreased protein turnover. For investigation of the mechanism of increased CD36 protein expression, metabolic turnover (pulsechase) studies of CD36 were performed in macrophages from $a b / o b$

\section{Figure 2}

CD36 protein turnover is decreased in ob/ob macrophages. Pooled WT or ob/ob macrophages were pulse-labeled with [ $\left.{ }^{35} \mathrm{~S}\right]$ methionine/cysteine cell-labeling mix for 20 minutes $(\mathbf{A})$ or 4 hours $(\mathbf{B})$, then chased in medium with methionine/cysteine for the times indicated. ${ }^{35}$ S-labeled CD36 in total lysates was immunoprecipitated with anti-CD36 and subjected to SDS-PAGE followed by transfer to nitrocellulose membrane and autoradiography. ${ }^{35} \mathrm{~S}$ intensities were quantified by densitometric analysis, and each number was normalized for input (measured by Western analysis of $\beta$-actin in lysates), then to the relative intensity at chase time 0 hours. For 20-minute and 4-hour labeling experiments, one experiment representative of two and four independent experiments, respectively, is shown. Macrophages were isolated from five to seven mice of each strain.

and wild-type mice. Short-term pulse labeling studies showed that the synthesis of CD36 protein was slightly reduced in $o b / o b$ macrophages compared with wild-type macrophages (Figure 2A). In contrast, CD36 protein turnover was markedly delayed in $o b / o b$ macrophages (Figure 2B), indicating that the accumulation of CD36 protein in these cells reflects decreased catabolism. The half-lives for CD36 protein in wild-type and $o b / o b$ macrophages were approximately 16 and 33 hours, respectively.

Decreased turnover of CD36 in ob/ob macrophages could reflect either decreased internalization from the cell surface or decreased degradation of CD36 after internalization. We used the approach of cell surface reversible biotinylation (27) with nonpermeant glutathione to measure the rate of internalization of CD36. The sample at 0 hours confirmed an increase in cell surface CD36 in ob/ob macrophages, as shown by biotinylation (Figure 3A, glutathione -). With this approach, cell surface biotinylated CD36 becomes pro-
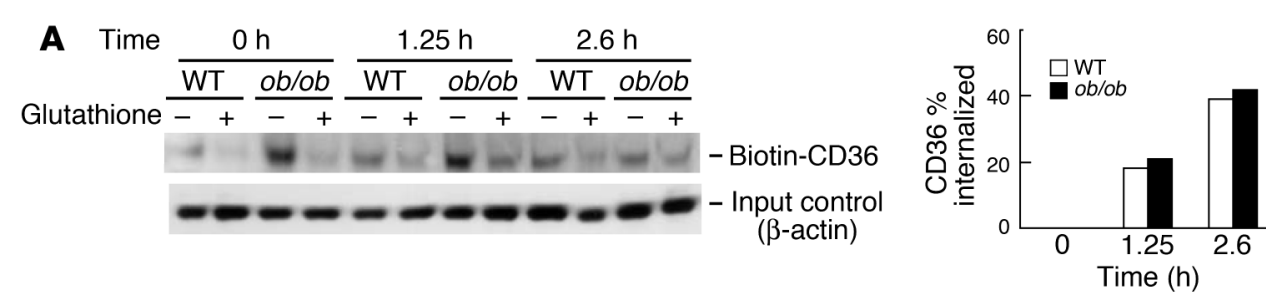

B
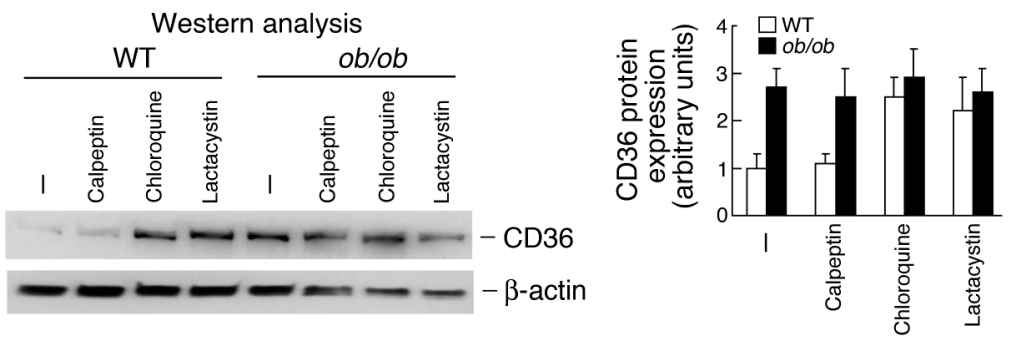

Figure 3

CD36 is internalized similarly in WT and ob/ob macrophages and is increased in lysosome- and proteasome-inhibited WT but not in ob/ob macrophages. (A) CD36 in ob/ob macrophages is endocytosed at a rate similar to that of WT cells. Cell surface proteins were biotinylated in pooled macrophages of five mice of each strain. One experiment representative of two independent experiments is shown. Biotinylated CD36 was allowed to internalize for different times, as indicated. Surface biotin was then removed with glutathione $(+)$. Cells without glutathione $(-)$ were used for the measurement of total biotinylated CD36 left in the cells at the time point. The total biotinylated CD36 at time 0 was used as a reference (100\%) for the quantification of internalized CD36 (all corrected for input with $\beta$-actin). Percent internalization was calculated as described (27). (B) CD36 protein is increased by lysosomal and proteasomal inhibitors in WT but not in ob/ob macrophages. Pooled macrophages isolated from five mice of each strain were treated with calpeptin $(30 \mu \mathrm{g} / \mathrm{ml})$, chloroquine $(50 \mu \mathrm{M})$, or lactacystin $(1 \mu \mathrm{M})$ for 1 day. Total lysates were prepared, and Western analysis was performed. One experiment representative of three independent experiments is shown. 
tected from glutathione only after internalization, resulting in the gradual appearance of a CD36 signal in the glutathione-treated samples shown in Figure 3A. These studies showed similar rates of fractional internalization of CD36 in $o b / o b$ and wild-type macrophages; for both, about $40 \%$ of surface CD36 was internalized after 2.6 hours (Figure 3A, right). To address whether the increased CD36 was caused by decreased activity of protein degradation pathways in $o b / o b$ macrophages, we used the inhibitors calpeptin, chloroquine, and lactacystin to block degradation by the calpain, lysosomal, and proteasomal pathways, respectively. Western analysis revealed that inhibition by chloroquine and lactacystin lead to two- to threefold increases in CD36 in wild-type but not in $o b / o b$ macrophages; calpeptin, however, had no effect on CD36 protein level in either wild-type or $o b / o b$ macrophages (Figure $3 \mathrm{~B}$ ). These results indicate that CD36 is undergoing degradation in both lysosomal and proteasomal pathways in wild-type macrophages but not in $o b / o b$ macrophages. Together with the increased cell surface concentration of CD36, these results imply that in $o b / o b$ macrophages, decreased entry of CD36 into degradation pathways is associated with increased recycling of CD36 to the cell surface.

Increased CD36 is not attributable to direct effects of leptin, glucose, insulin, or fatty acids on macrophages. We next considered the potential relationships of several different metabolic abnormalities in $o b / o b$ mice to increased CD36 protein in macrophages. Treatment with leptin $(62.5 \mathrm{nM})$ had no effect on cell association or cholesterol esterification using acLDL in either wild-type or $o b / o b$ macrophages (Figure $1, \mathrm{~A}-\mathrm{C})$, indicating that the defect was not related to a direct action of leptin on macrophages. Short-term treatment with insulin (10 $\mathrm{nM}$ ) also had no effect on these parameters. Furthermore, shortterm treatment of wild-type macrophages with either insulin or PI3 kinase inhibitors did not alter CD36 protein levels or binding of oxLDL, indicating that increased CD36 was unrelated to a direct effect of insulin or signaling via PI3 kinase (Figure 4A). Obese $o b / o b$ mice are hyperglycemic and have increased levels of plasma free fatty acids (17). Treatment of wild-type macrophages for 2 days with increasing amounts of glucose in medium resulted in decreased binding of oxLDL, compared with isosmotic control experiments carried out with mannitol in medium (Figure 4B). Western analysis showed that CD36 expression was lower in glucose- than in mannitol-incubated macrophages (Figure 4B), consistent with oxLDL binding data. Similar results were obtained with mouse blood monocytes incubated with mannitol or glucose (Figure 4C). In addition, short-term treatment ( 2 hours) of wild-type macrophages with $400 \mathrm{mg} / \mathrm{dl}$ of glucose or mannitol had no effect on binding of oxLDL (data not shown). Increasing amounts of free fatty acids within the physiological range did not lead to an increase in CD36 protein (Figure 4D). Thus, the increase in CD36 is not explained by increased plasma glucose or free fatty acids.

Signaling through IRs is defective in ob/ob macrophages. These observations led us to consider that increased CD36 might result from a form of insulin resistance, acting at the level of the macrophage. However, there is a paucity of information on IRs and insulin signaling in macrophages. Thus, as a prelude to a more detailed examination of the insulin resistance hypothesis, we first examined IRs and their signaling in wild-type and $o b / o b$ macrophages (Figure 5). These studies showed that IRs are depleted $(0.4 \pm 0.2)$ in $o b / o b$ macrophages, comparable to the reduction of IRs in $o b / o b$ livers (Figure 5A). IR function was assessed by measurement of tyrosine phosphorylation. Insulin treatment caused tyrosine phosphorylation of IRs in macrophages from both types of mice. However, in $o b / o b$ macrophages, the dose-response curve was shifted to the right, as shown by markedly reduced signaling at 1 and $10 \mathrm{nM}$ insulin (Figure 5B; plasma insulin concentrations are about $4 \mathrm{nM}$ in $o b / o b$ mice). To assess downstream signaling events, we measured phosphorylation of IRS-2 (IRS-1 was undetectable in macrophages) and found phosphorylation was markedly reduced (Figure 5C); furthermore, the dose-response of IRS- 2 phosphorylation was also shifted to the right in $o b / o b$ macrophages (data not shown). These results indicate reduced IR phosphorylation and downstream signaling in $o b / o b$ macrophages.

Defective insulin signaling in macrophages leads to increased CD36. The finding of reduced levels and tyrosine phosphorylation of both IRs and IRS-2 indicates defective insulin signaling in $o b / o b$ macro-
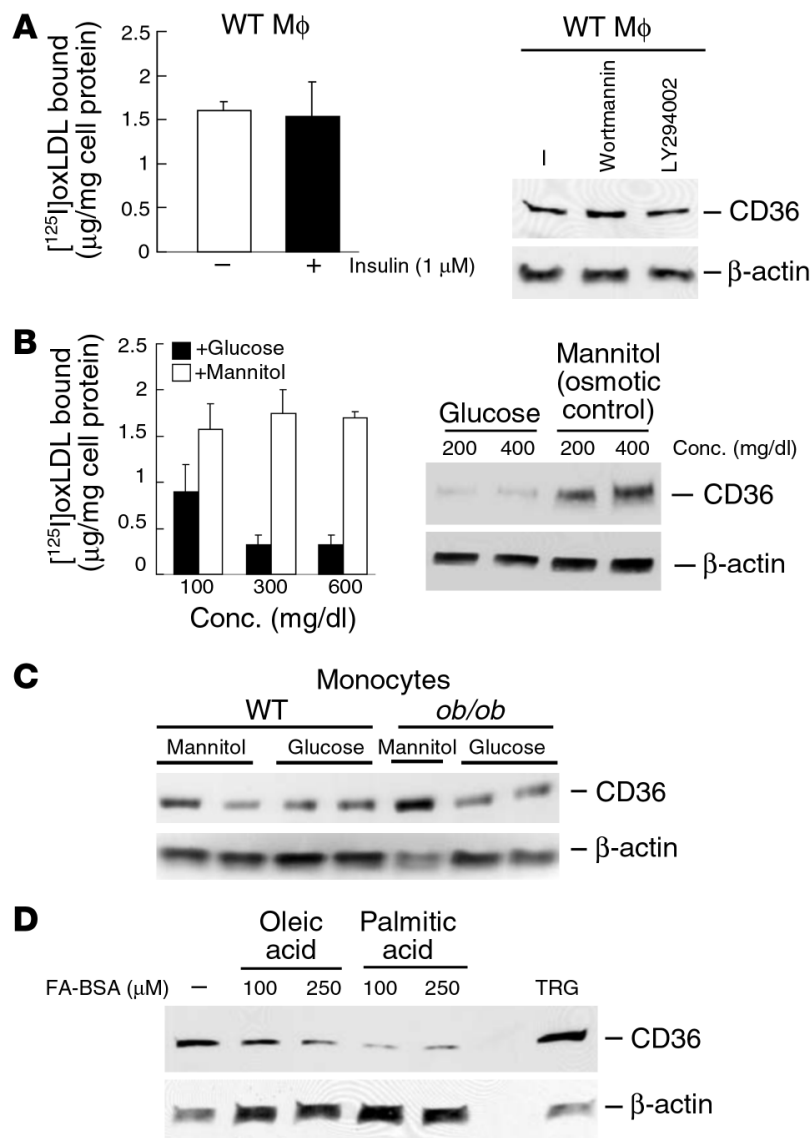

\section{Figure 4}

Short-term treatment with insulin or PI3 kinase inhibitors, or long-term treatment with glucose or fatty acids, does not increase CD36 protein expression in WT macrophages. (A-D) Pooled WT macrophages (A, $\mathbf{B}$, and $\mathbf{D}$ ) or WT and ob/ob monocytes (C) isolated from three to ten mice were incubated with insulin $(1 \mu \mathrm{M})$ for 0.5 hours or with the PI3 kinase inhibitors wortmannin (200 nM) or LY294002 (20 $\mu \mathrm{M})$ for 2 hours (A), with glucose or mannitol at the indicated concentrations for 2 days (B), with $400 \mathrm{mg} / \mathrm{dl}$ of glucose or mannitol for 1 day (C), or with oleic acid- or palmitic acid-BSA complexes for 1 day (D). Troglitazone (TRG; $1 \mu \mathrm{M})$ was used as a positive control. Treated cells were then used for oxLDL binding assays with the SR-A ligand fucoidan $(50 \mu \mathrm{g} / \mathrm{ml})$ added to the binding buffer or for total protein extraction followed by Western analysis. One experiment representative of two (A, B, and $\mathbf{D})$ or three (B) independent experiments is shown. $\mathrm{M} \phi$, macrophage; $\mathrm{FA}$, fatty acid; Conc., concentration. 


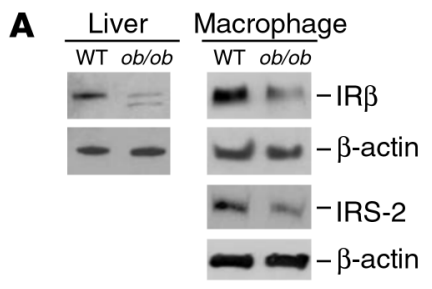

B

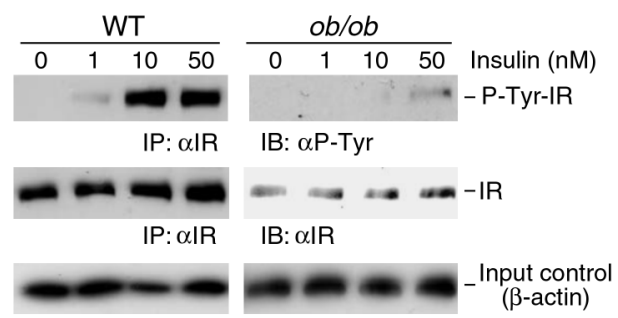

IB: $\alpha$-actin

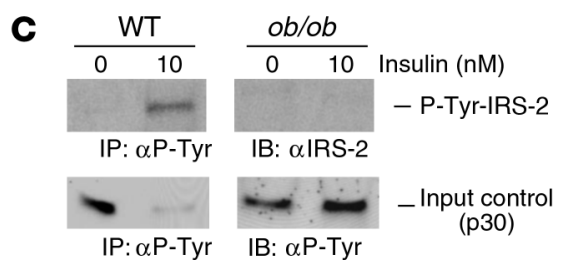

phages. We used three different approaches to test the hypothesis that defective insulin signaling could lead to increased CD36 protein in macrophages. In the first, we exposed macrophages to longterm treatment ( 24 hours) with high-dose insulin $(100 \mathrm{nM})$, a procedure that is known to cause decreased IRs and defective signaling in other cell types (30). This treatment reduced IR levels $(0.5 \pm 0.2)$, increased CD36 protein (1.5- to 2 -fold), and increased binding of oxLDL (1.5- to 2 -fold) in wild-type but not $o b / o b$ macrophages (Figure $6 \mathrm{~A}$ ). The lack of response in $o b / o b$ macrophages reflects the fact

\section{Figure 6}

Defects in insulin signaling in mouse macrophages increase oxLDL binding and CD36 protein expression. (A) Ex vivo effects of chronic high-dose insulin on insulin receptor $\beta$-subunit (far left) and CD36 protein expression (middle panels), and oxLDL binding to WT and ob/ob macrophages (far right). Macrophages were incubated with (+) or without (-) insulin (200 $\mathrm{nM}$ ) for 1 day. Cells were used for oxLDL binding assays or Western analysis with the indicated antibodies. (B) The increase in CD36 protein expression in WT macrophages by the PI3 kinase inhibitor wortmannin is dose dependent. WT or ob/ob macrophages were treated with wortmannin at the indicated concentrations or another inhibitor, LY294002 (LY; 10 $\mu \mathrm{M})$, for 1 day, followed by protein extraction and Western analysis (left) and by oxLDL binding assays with fucoidan $(50 \mu \mathrm{g} / \mathrm{ml})$ in the binding buffer (right). Inhibition of the insulin receptor effector PI3 kinase results in an increase in oxLDL binding to macrophages. (C) TNF- $\alpha$ has no effect on CD36 protein expression. WT macrophages were treated with LY294002 (LY; $10 \mu \mathrm{M})$ or TNF- $\alpha$ (10 ng/ml) for 1 day. Total lysates were prepared and Western analysis was performed. (D) CD36 protein expression is reduced by $10 \%$ FBS in ob/ob and WT macrophages. Insulin receptors are increased under this condition. All experiments were performed with pooled macrophages isolated from three to six mice of each strain indicated. One experiment representative of three independent experiments is shown.

\section{Figure 5}

The expression and signaling of insulin receptor is downregulated in ob/ob versus WT macrophages. (A) Insulin receptor $\beta$-subunit (IR $\beta$ ) expression is decreased in pooled ob/ob compared with WT macrophages isolated from six mice of each strain, as determined by Western analysis. One experiment representative of three independent experiments is shown. A similar expression pattern is also found in $o b / o b$ liver. (B and $\mathbf{C}$ ) Insulin-dependent tyrosine phosphorylation of IR (B) and IRS-2 (C) in ob/ob macrophages is defective, even at a higher insulin concentration ( $10 \mathrm{nM}$ ) than ob/ob plasma insulin levels (about $4 \mathrm{nM})$. Ex vivo tyrosine phosphorylation of IR or IRS-2 by IR tyrosine kinase in response to insulin in ${ }^{32} \mathrm{P}$-preincubated pooled $\mathrm{ob} / \mathrm{ob}$ and WT macrophages isolated from five mice each was performed for 10 minutes. Total protein lysates were then subjected to immunoprecipitation with anti-IR or anti-phosphotyrosine ( $\alpha$ P-Tyr) and separated by SDS-PAGE followed by membrane transfer and ${ }^{32} \mathrm{P}$ autoradiography. The membranes were then probed with anti-P-Tyr or anti-IR (for IR) or with anti-IRS-2, respectively. In C (bottom), P-Tyr p30 whose tyrosine phosphorylation status was not affected by insulin is shown to reflect the amounts of initial extracts used for immunoprecipitation of phosphoproteins. One experiment representative of two independent experiments is shown. IP, immunoprecipitation; IB, immunoblotting.

that IRs are already markedly depleted (Figure $5 \mathrm{~A}$ ) and is consistent with the idea that downregulation of IRs is the major mechanism that accounts for the increase in CD36.

PI3 kinase is a major downstream effector of IR signaling via either IRS-1 or IRS-2 (31). Thus, in the second approach we treated macrophages with wortmannin or LY294002, two different inhibitors of PI3 kinase. Both treatments resulted in a dramatic induction of CD36 protein (two-to fivefold, depending on the doses of inhibitors used) in wild-type but not $o b / o b$ macrophages and a
A

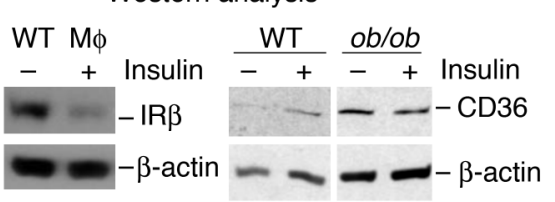

B

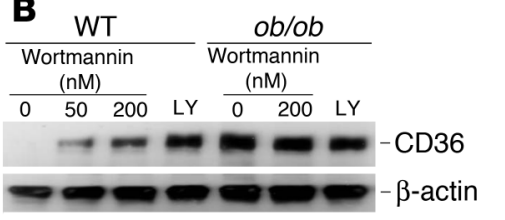

C

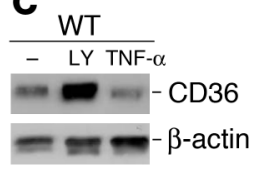

D
Total OxLDL binding
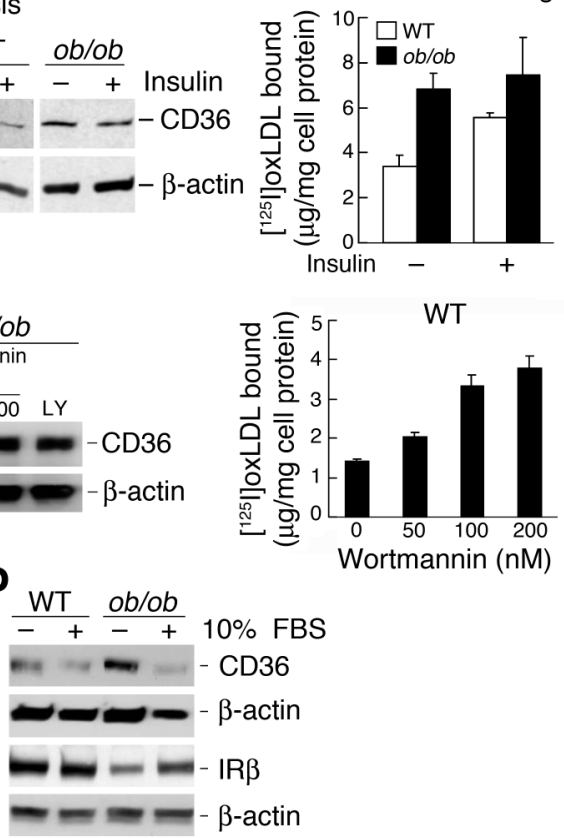
A
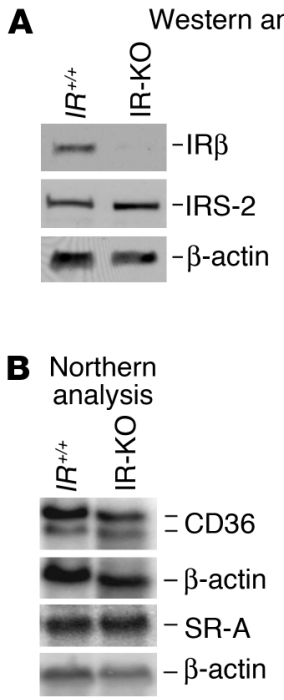

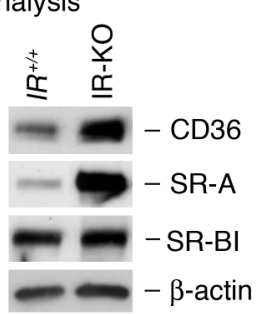

C

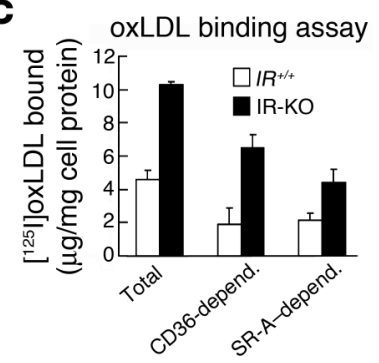

parallel increase in binding of oxLDL to wild-type macrophages (Figure 6B). In contrast, CD36 mRNA was minimally induced by PI3 kinase inhibition (1.2- to 1.5-fold; data not shown). TNF- $\alpha$, another factor that may induce insulin resistance in mice (32), did not result in increased CD36 protein (Figure 6C). When $o b / o b$ macrophages were cultured for 24 or 48 hours in FBS, there was partial or complete reversal in the defective expression of IRs and CD36, respectively (Figure 6D), and a partial reversal in CD36 protein turnover (data not shown), suggesting that the defect in $o b / o b$ macrophages was not cell autonomous. These results are consistent with the idea of defective IR signaling as the underlying cause of increased CD36 in $o b / o b$ macrophages.

In a third genetic approach, we used macrophages from transgenically rescued IR KO mice. These mice express human IRs exclusively in the liver, islets, and brain, and are not diabetic $(19,20)$. Macrophages from these mice lacked IRs, showed normal IRS-2 (Figure $7 \mathrm{~A}$ ), and showed increased binding of oxLDL and increased CD36 (2.8 \pm 0.6 -fold) and SRA protein ( $3.6 \pm 1.1$-fold) but not

\section{Figure 8}

Treatment of $o b / o b$ mice with rosiglitazone improves insulin resistance and normalizes oxLDL binding and CD36 protein expression in macrophages. (A) In vivo rosiglitazone (RSG) treatment reduces plasma glucose levels and oxLDL binding to macrophages in ob/ob mice. Plasma glucose levels (left) and macrophage oxLDL binding (right) were assessed in ob/ob mice treated with rosiglitazone or control saline. At the times indicated, plasma glucose levels from these mice were measured. After 3 weeks, macrophages were collected and an oxLDL binding assay was performed with the addition of fucoidan $(50 \mu \mathrm{g} / \mathrm{ml})$ in the binding buffer. (B) Differential patterns of CD36 protein expression in $o b / o b$ macrophages in response to thiazolidinedione treatments in vivo and ex vivo. Left, Western analysis of CD36 protein expression in ob/ob and WT macrophages treated ex vivo with RSG or troglitazone (TRG) at the indicated doses for 1 day. Right, the expression of CD36 and IR $\beta$-subunit (IR $\beta$ ) protein in macrophages from ob/ob mice described in $\mathbf{A}$ was determined by Western analysis. Macrophage CD36 protein was normalized in ob/ob mice, though its mRNA was increased by rosiglitazone in vivo, as measured by Northern analysis. Macrophage experiments were performed with pooled cells isolated from three to five mice of each strain indicated. One experiment representative of two independent experiments is shown.

\section{Figure 7}

Lack of insulin receptors in peritoneal macrophages leads to upregulation of CD36 protein expression and oxLDL binding. (A) Western analysis of macrophage IR $\beta$ subunit, IRS-2, CD36, SR-A, and SR-BI protein expression in IR knockout (IR-KO) mice rescued with the human IR transgene and in control littermate $\left(I R^{+/+}\right)$mice. Both CD36 and SR-A protein are increased in IR-deficient macrophages. (B) Northern analysis of CD36 and SR-A mRNA levels in macrophages of IR-KO and $I R^{+/+}$mice. (C) Assay of oxLDL binding to macrophages from IR-KO and control IIR+/+ was carried out with or without the addition of fucoidan $(50 \mu \mathrm{g} / \mathrm{ml})$, mouse antiCD36 IgA (20 $\mu \mathrm{g} / \mathrm{ml})$, or control IgA $(20 \mu \mathrm{g} / \mathrm{ml}$; not shown) in the binding buffer. CD36-depend. and SR-A-depend., oxLDL binding mediated by CD36 and SR-A, respectively. All experiments were performed with pooled macrophages isolated from three to five mice of each strain. One experiment representative of three independent experiments is shown.

mRNA (Figure 7), similar to $o b / o b$ mice. Treatments with fucoidan and anti-CD36 indicated that increased CD36 in IR KO mice was the major cause of increased binding of oxLDL (Figure 7C). Thus, genetic deficiency of IRs in macrophages leads to the same defect in CD36 protein expression as genetic obesity, consistent with defective insulin signaling through the macrophage IR as the major underlying mechanism.

PPAR- $\gamma$ activators decrease macrophage CD36 protein in vivo but not ex vivo. If insulin resistance is the underlying reason for increased CD36 in $o b / o b$ macrophages, then reversal of insulin resistance in vivo by treatment with thiazolidinediones should lead to a reversal of the macrophage phenotype. Treatment of $o b / o b$ mice with

A

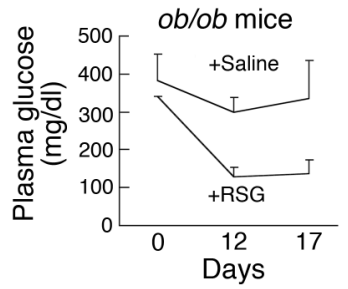

B Ex vivo treatment Western analysis
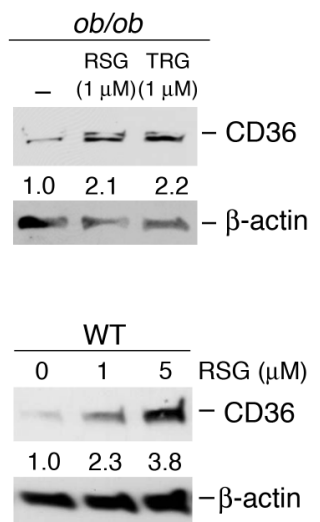

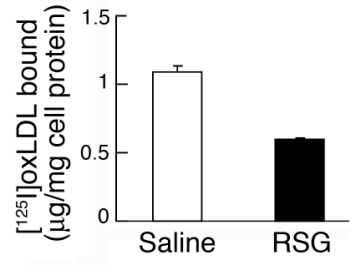

In vivo treatment Western analysis

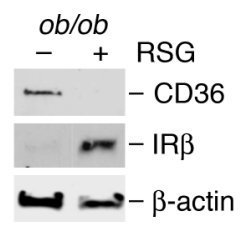

Northern analysis

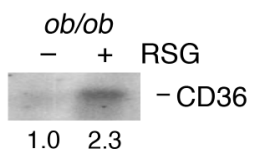




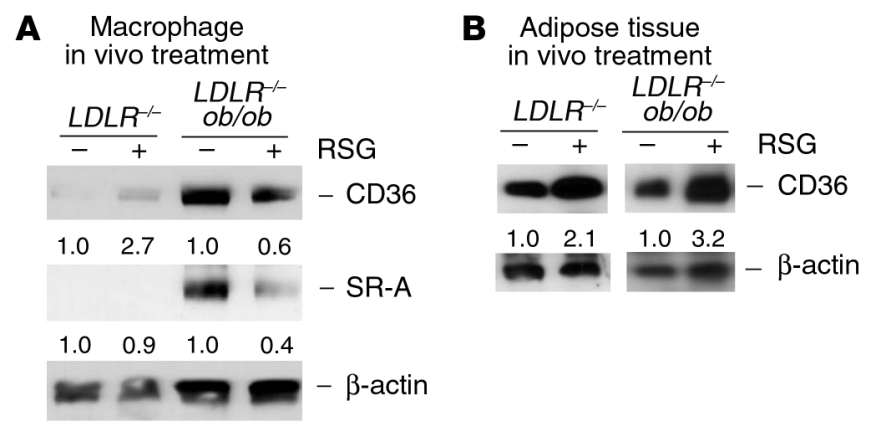

Figure 9

In vivo treatment with rosiglitazone reduces macrophage CD36 protein expression in ob/ob $L D L R^{-/-}$mice while increasing its expression in $L D L R^{-1-}$ mice. (A) Western analysis of macrophage CD36 and SR-A protein expression from mice with or without rosiglitazone (RSG) treatment for 3 weeks as described in Methods. (B) For comparison, the expression of CD36 protein in adipose tissue of mice described in $\mathbf{A}$ was determined by Western analysis. CD36 protein is upregulated by PPAR- $\gamma$ activator in adipose tissue of both ob/ob $L D L R^{-/-}$and $L D L R^{-1-}$ mice. All mice treated with RSG showed a similar increase in CD36 protein expression in adipose tissue, and results from one mouse of each strain were shown here. Macrophage experiments were performed with pooled cells isolated from three mice of each strain. One experiment representative of two independent experiments is shown.

rosiglitazone, a PPAR- $\gamma$ activator, resulted in a marked reduction of blood glucose levels (threefold; Figure 8A) and of plasma insulin levels (data not shown), indicative of decreased insulin resistance in these animals (33). This was associated with a reversal of the macrophage phenotype with upregulation of IRs (Figure 8B), decreased binding of oxLDL (Figure 8A), and decreased CD36 protein but not CD36 mRNA (CD36 mRNA was actually increased; Figure $8 \mathrm{~B}$ ). In contrast, ex vivo treatment of $o b / o b$ or wild-type macrophages with thiazolidinediones resulted in two- to fourfold increased CD36 protein (Figure 8B), as reported (12). These results suggest that in vivo improvement of insulin resistance by PPAR- $\gamma$ activators led to decreased macrophage CD36 expression, predominating over any possible increase in CD36 related to direct effects of PPAR- $\gamma$ activators in the macrophage.

To assess the potential relevance of these observations to atherogenesis, similar experiments were conducted in $L D L R^{-/-}$and $o b / o b$ $L D L R^{-/-}$mice, since the latter show markedly increased atherosclerosis compared with the former (18). As shown in Figure 9A, this confirmed a reduction in CD36 (40\% decrease) and SR-A protein (60\% decrease), along with decreased plasma glucose and insulin levels (data not shown), in the $o b / o b L D L R^{-/-}$mice; the effect was not as dramatic as that shown in Figure 8, probably because we had to use a reduced dose of rosiglitazone due to toxicity at the higher dose in $o b / o b L D L R^{-/-}$mice. In contrast, in the control $L D L R^{-/-}$ mice, CD36 protein was induced threefold by rosiglitazone treatment (Figure 9A). This is consistent with a reversal of obesity-associated insulin resistance as the major mechanism responsible for decreased CD36 in the $o b / o b L D L R^{-/-}$mice. In contrast to the response in macrophages, both CD36 mRNA (three- to fourfold; data not shown) and protein (two- to fourfold; Figure 9B) were increased in adipose tissue from rosiglitazone-treated $o b / o b$ $L D L R^{-/-}$mice, indicating a differential response in macrophages and adipose tissue.

\section{Discussion}

This study documents defective insulin signaling in macrophages from $o b / o b$ mice and provides evidence that this leads to a post-transcriptional increase in CD36. As CD36 is a key molecule in the recognition of modified LDL (34), our findings suggest that insulin resistance at the level of the macrophage predisposes to atherosclerosis and represents a new mechanism to explain increased atherogenesis in insulin resistant states such as metabolic syndrome and type II diabetes. Moreover, this abnormality is reversed by treatment of

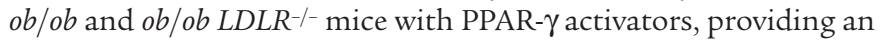
explanation for the known antiatherogenic effects of these agents that is closely linked to their main mechanism of action; that is, improvements in insulin signaling $(8,9)$.

Surprisingly, there is only sparse evidence in the literature indicating the presence of IRs and insulin signaling in macrophages. Older studies showing high-affinity binding of insulin to monocytes and macrophages implied the existence of such receptors (7); moreover, reduced insulin binding to monocytes of obese people has been documented (35), suggesting a depletion of IRs similar to that observed in $o b / o b$ mice in this study. However, there is a relative paucity of information on macrophage insulin signaling and its relationship to normal or abnormal macrophage functions (36-38), in contrast to the detailed studies carried out with other insulin-sensitive tissues (31). Our studies revealed abundant IRs and insulin signaling via IRS-2 in normal macrophages. The physiological significance of insulin signaling remains unclear, as the constitutive GLUT-1 glucose transporter, rather than the insulin-inducible GLUT-4 $(39,40)$, is the main isoform expressed in macrophages, and insulin had no direct effect on glucose uptake by mouse macrophages (data not shown). While a role for insulin signaling in macrophage phagocytosis could be suspected, studies of insulin effects on this process have yielded inconsistent results $(7,41)$.

Our studies link defective insulin signaling in macrophages to an increase in CD36 protein. Part of the evidence for this was that IRdeficient macrophages obtained from IR-transgenic/KO mice also displayed increased CD36 protein, but reduced CD36 mRNA, similar to $o b / o b$ macrophages. However, like $o b / o b$ mice, the IR KO animals have insulin resistance, so these findings alone do not rule out the possibility that the increase in CD36 was secondary to insulin resistance in the whole animal rather than a direct effect of genetic deficiency of IRs in macrophages. However, the downregulation of IRs by high-dose insulin treatment or treatment with PI3 kinase inhibitors in cultured normal macrophages also led to increased CD36 protein, providing further evidence that CD36 is increased as a direct result of decreased insulin signaling in the macrophage. Also consistent with this hypothesis, a number of alternative explanations, such as direct effects of leptin, glucose, or fatty acids on macrophages, were excluded in cell culture experiments. IR-transgenic/KO mice expressing human IRs only in liver, islets, and brain do not have hyperglycemia (20) and their plasma free fatty acids are normal (data not shown), providing additional evidence to support the direct ex vivo evidence that increased glucose and fatty acids did not lead to an increase in CD36 protein in macrophages.

The mechanism responsible for decreased IRs and signaling in $o b / o b$ mice is unknown but could reflect changes in humoral factors associated with insulin resistance, such as hyperinsulinemia, and altered levels of plasma factors such as adiponectin (42-44) or resistin (45). Surprisingly, insulin resistance led to a delay in the cellular catabolism of CD36 protein. Studies with inhibitors suggest a defect in degradation of CD36 in lysosomes and proteasomes of $o b / o b$ 
macrophages. As this is associated with an increase in cell surface CD36 that does not reflect a defect in internalization, increased recycling of CD36 to the cell surface is implied. Thus, a defect in insulin signaling appears to lead to a defect in receptor trafficking. The resultant buildup of CD36 protein leads to increased binding, uptake, and degradation of modified LDL in $o b / o b$ macrophages (Figure 1). Presumably the modified LDL dissociates from CD36 in early endosomes following internalization and enters lysosomal degradation pathways, while CD36 itself undergoes recycling.

In an earlier study, Griffin et al. (46) reported a post-transcriptional increase in CD36 in diabetic macrophages, similar to our findings. However, this effect was attributed to increased CD36 protein translation, related to hyperglycemia. For unknown reasons, we could not confirm such an effect of increased glucose levels on CD36 protein expression in mouse peritoneal macrophages or blood monocytes. Subsequent studies have not confirmed the increase in CD36 expression ex vivo by glucose in human blood monocytes (47). Moreover, broader considerations call into question the link between hyperglycemia and atherosclerosis. Hyperglycemia is not well correlated with atherosclerosis risk in humans. For example, in the UK Prospective Diabetes Trial, higher levels of hemoglobin $\mathrm{A}_{1 \mathrm{C}}$ levels, reflecting poorer control of hyperglycemia, were associated with a much higher incidence of microvascular disease but only slightly increased macrovascular disease $(3,4)$. In the majority of studies in mouse models of atherosclerosis, hyperglycemia per se does not increase atherosclerosis $(48,49)$. Thus, we have made an important advance on the original observation of increased CD36 in diabetic macrophages by linking this phenotype to defective macrophage insulin signaling. Our findings may be relevant to the increased atherogenic risk in metabolic syndrome, a highly prevalent condition associated with insulin resistance in the absence of frank hyperglycemia.

CD36 has emerged as a key proatherogenic molecule $(34,50)$, potentially mediating binding of LDL containing as few as two or three appropriately modified phospholipid molecules (51). Mice deficient in both CD36 and apoE show reduced atherosclerosis compared with apoE KO controls (50). Although not the primary focus of the present study, $o b / o b$ and IR-deficient mice also showed upregulation of macrophage scavenger receptor A via post-transcriptional mechanisms; this could also predispose to atherosclerosis. SR-A recognizes only LDL that has been extensively modified, and studies with SR-A $\mathrm{KO}$ mice have indicated somewhat variable atherosclerosis results (52). There appear to be multiple pathways by which macrophages take up modified forms of LDL, including the uptake of aggregated LDL produced by arterial sphingomyelinase or other factors. These pathways may involve engulfment and prolonged cell surface contact with immobilized, aggregated LDL, and require remodeling of the actin cytoskeleton, a process known to be regulated by PI3 kinase signaling (24). Such pathways could also potentially be regulated by changes in PI3 kinase activity associated with macrophage insulin resistance.

PPAR- $\gamma$ activators have emerged as an important treatment of type II diabetes. Since the discovery that PPAR- $\gamma$ activators, including hydroxyoctadecadienoic acids present in oxLDL, increase transcription of CD36, there has been concern that PPAR- $\gamma$ activators could worsen atherosclerosis. This concern has only been partly allayed by mouse atherosclerosis studies (8-11) and a single small human study suggesting benefit on carotid intimal thickening (53). One potential beneficial effect of PPAR- $\gamma$ activators in macrophages is a decrease in inflammatory responses (54); indeed, these drugs cause a widespread decrease in expression of macrophage inflammatory genes (55). Our studies indicate an additional possibly indirect effect of these agents; that is, a decrease in insulin resistance that leads to an improvement in insulin signaling and a decrease in macrophage CD36. However, this beneficial effect was seen only in a model of severe insulin resistance, that is, the $o b / o b$ mouse, whereas LDLRdeficient mice fed a Western diet that have milder insulin resistance actually showed an increase in CD36 protein after rosiglitazone treatment (Figure 9A). This suggests that direct effects of thiazolidinedione on CD36 gene expression may predominate in the setting of mild insulin resistance. Thus, the effects of these drugs on atherogenesis could differ depending on the degree of insulin resistance. Our findings focus attention on macrophage insulin signaling as a key parameter potentially determining atherogenic responses and suggest that further studies of this pathway may be rewarding for understanding of both the normal functions of macrophages and also defects in insulin signaling that could contribute to impairment of innate immunity and to atherosclerosis in metabolic syndrome and diabetes.

\section{Acknowledgments}

We thank Wengen Chen for help in cholesterol efflux experiments. This work was supported by NIH grants HL22682 and DK58282.

Received for publication July 18, 2003, and accepted in revised form December 15, 2003.

Address correspondence to: Chien-Ping Liang, Division of Molecular Medicine, Department of Medicine, Columbia University, 630 West 168th Street, New York, New York 10032, USA. Phone: (212) 305-4899; Fax: (212) 305-5052; E-mail: CL534@columbia.edu.
1. Haffner, S.M., Lehto, S., Ronnemaa, T., Pyorala, K., and Laakso, M. 1998. Mortality from coronary heart disease in subjects with type 2 diabetes and in nondiabetic subjects with and without prior myocardial infarction. N. Engl. J. Med. 339:229-234.

2. Ginsberg, H.N. 2000. Insulin resistance and cardiovascular disease. J. Clin. Invest. 106:453-458.

3. Reaven, G.M. 2002. Multiple CHD risk factors in type 2 diabetes: beyond hyperglycaemia. Diabetes Obes. Metab. 4:S13-S18.

4. Haffner, S.M. 2002. Lipoprotein disorders associated with type 2 diabetes mellitus and insulin resistance. Am. J. Cardiol. 90:55i-61i.

5. Steinberg, H.O., and Baron, A.D. 2002. Vascular function, insulin resistance and fatty acids. Diabetologia. 45:623-634.

6. Vicent, D., et al. 2003. The role of endothelial insulin signaling in the regulation of vascular tone and insulin resistance. J. Clin. Invest. 111:1373-1380. doi:10.1172/JCI200315211.

7. Bar, R.S., Kahn, C.R., and Koren, H.S. 1977. Insulin inhibition of antibody-dependent cytoxicity and insulin receptors in macrophages. Nature. 265:632-635.

8. Li, A.C., et al. 2000. Peroxisome proliferator-activated receptor gamma ligands inhibit development of atherosclerosis in LDL receptor-deficient mice. J. Clin. Invest. 106:523-531.

9. Collins, A.R., et al. 2001. Troglitazone inhibits formation of early atherosclerotic lesions in diabetic and nondiabetic low density lipoprotein receptor-deficient mice. Arterioscler. Thromb. Vasc. Biol. 21:365-371.

10. Chen, Z., et al. 2001. Troglitazone inhibits atherosclerosis in apolipoprotein E-knockout mice: pleiotropic effects on CD36 expression and HDL. Arterioscler. Thromb. Vasc. Biol. 21:372-377.

11. Lee, C-H., and Evans, R.M. 2002. Peroxisome prolif- erator-activated receptor- $\gamma$ in macrophage lipid homeostasis. Trends Endocrinol. Metab. 13:331-335.

12. Moore, K.J., et al. 2001. The role of PPAR- $\gamma$ in macrophage differentiation and cholesterol uptake. Nat. Med. 7:41-47.

13. Chawla, A., et al. 2001. A PPAR gamma LXR-ABCA1 pathway in macrophages is involved in cholesterol efflux and atherogenesis. Mol. Cell 7:161-171.

14. Chinetti, G., et al. 2001. PPAR- $\alpha$ and PPAR- $\gamma$ activators induce cholesterol removal from human macrophage foam cells through stimulation of the ABCA1 pathway. Nat. Med. 7:53-58.

15. Akiyama, T.E., et al. 2001. Conditional disruption of the peroxisome proliferator-activated receptor gamma gene in mice results in lowered expression of ABCA1, ABCG1, and apoE in macrophages and reduced cholesterol efflux. Mol. Cell. Biol. 22:2607-2619. 
16. Claudel, T., et al. 2001. Reduction of atherosclerosis in apolipoprotein $\mathrm{E}$ knockout mice by activation of the retinoid X receptor. Proc. Natl. Acad. Sci. U. S. A. 298:2610-2615.

17. Reitman, M.L. 2000. Rodent genetic models of obesity and type 2 diabetes mellitus. In Diabetes mellitus: a fundamental and clinical text. 2nd edition. D. LeRoith, S.I. Taylor, and J.M. Olefsky, editors. Lippincott Williams \& Wilkins Publishers. Philadelphia, Pennsylvania, USA. 723-734.

18. Hasty, A.H., et al. 2001. Severe hypercholesterolemia, hypertriglyceridemia, and atherosclerosis in mice lacking both leptin and the low density lipoprotein receptor. J. Biol. Chem. 276:37402-37408.

19. Accili, D., et al. 1996. Early neonatal death in mice homozygous for a null allele of the insulin receptor gene. Nat. Genet. 12:106-109.

20. Okamoto, H., Nakae, J., Kitamura, T., Park, B.-C., and Accili, D. 2002. Prevention of diabetes in mice lacking insulin receptors requires restoration of insulin action in liver, pancreatic beta cells and brain. Diabetes. 51:A328.

21. Chen, W., et al. 2001. Preferential ATP-binding cassette transporter A1-mediated cholesterol efflux from late endosomes/lysosomes. J. Biol. Chem. 276:43564-43569.

22. Graziani-Bowering, G.M., Graham, J.M., and Filion, L.G. 1997. A quick, easy and inexpensive method for the isolation of human peripheral blood monocytes. J. Immunol. Methods. 207:157-168.

23. Goldstein, J.L., Basu, S.K., and Brown, M.S. 1983. Receptor-mediated endocytosis of low-density lipoprotein in cultured cells. Methods Enzymol. 98:241-260.

24. Sakr, S.W., et al. 2001. The uptake and degradation of matrix-bound lipoproteins by macrophages require an intact actin cytoskeleton, Rho family GTPases, and myosin ATPase activity. J. Biol. Chem. 276:37649-37658.

25. Kunjathoor, V.V., et al. 2002. Scavenger receptors class A-I/II and CD36 are the principal receptors responsible for the uptake of modified low density lipoprotein leading to lipid loading in macrophages. J. Biol. Chem. 277:49982-84998.

26. Hannah, V.C., Ou, J., Luong, A., Goldstein, J.L., and Brown, M.S. 2001. Unsaturated fatty acids down-regulate srebp isoforms $1 \mathrm{a}$ and $1 \mathrm{c}$ by two mechanisms in HEK-293 cells. J. Biol. Chem. 276:4365-4372.

27. Schramm, N.L., and Limbird, L.E. 1999. Stimulation of mitogen-activated protein kinase by $G$ protein-coupled $\alpha_{2}$-adrenergic receptors does not require agonist-elicited endocytosis. J. Biol. Chem. 274:24935-24940.

28. Liang, C.P., and Tall, A.R. 2001. Transcriptional profiling reveals global defects in energy metabolism, lipoprotein, and bile acid synthesis and transport with reversal by leptin treatment in ob/ob mouse liver. J. Biol. Chem. 276:49066-49076.

29. Krieger, M., and Herz, J. 1994. Structures and functions of multiligand lipoprotein receptors: macrophage scavenger receptors and LDL receptorrelated protein (LRP). Annu. Rev. Biochem. 63:601-637.

30. Knutson, V.P., Donnelly, P.V., Balba, Y., and LopezReyes, M. 1995. Insulin resistance is mediated by a proteolytic fragment of the insulin receptor. J. Biol. Chem. 270:24972-24981.

31. Saltiel, A.R., and Kahn, C.R. 2001. Insulin signalling and the regulation of glucose and lipid metabolism. Nature. 414:799-806.

32. Peraldi, P., Xu, M., and Spiegelman, B.M. 1997. Thiazolidinediones block tumor necrosis factor- $\alpha$ induced inhibition of insulin signaling. J. Clin. Invest. 100:1863-1869.

33. Chao, L., et al. 2000. Adipose tissue is required for the antidiabetic, but not for the hypolipidemic, effect of thiazolidinediones. J. Clin. Invest. 106:1221-1228.

34. Febbraio, M., Hajjar, D.P., and Silverstein, R.L. 2001. CD36: a class B scavenger receptor involved in angiogenesis, atherosclerosis, inflammation, and lipid metabolism. J. Clin. Invest. 108:785-791. doi:10.1172/ JCI200114006.

35. Bar, R.S., Gorden, P., Roth, J., Kahn, C.R., and De Meyts, P. 1976. Fluctuations in the affinity and concentration of insulin receptors on circulating monocytes of obese patients: effects of starvation, refeeding, and dieting. J. Clin. Invest. 58:1123-1135.

36. Welham, M.J., et al. 1997. Insulin receptor substrate2 is the major $170-\mathrm{kDa}$ protein phosphorylated on tyrosine in response to cytokines in murine lymphohemopoietic cells. J. Biol. Chem. 272:1377-1381.

37. Frittitta, L., Grasso, G., Munguira, M.E., Vigneri, R., and Trischitta, V. 1993. Insulin receptor tyrosine kinase activity is reduced in monocytes from nonobese normoglycaemic insulin-resistant subjects. Diabetologia. 36:1163-1167.

38. Zoppini, G., Galante, P., Zardini, M., and Muggeo, M. 1994. Phosphotyrosine protein profiles in monocytes after insulin and IGF-1 stimulation. Eur. J. Clin. Invest. 24:275-278.

39. Malide, D., Davies-Hill, T.M., Levine, M., and Simpson, I.A. 1998. Distinct localization of GLUT-1, -3, and -5 in human monocyte-derived macrophages: effects of cell activation. Am. J. Physiol. 274:E516-E526.

40. Laffitte, B.A., et al. 2003. Activation of liver X receptor improves glucose tolerance through coordinate regulation of glucose metabolism in liver and adipose tissue. Proc. Natl. Acad. Sci. U. S. A. 100:5419-5424.

41. Rosa, L.F., Cury, Y., and Curi, R. 1992. Effects of insulin, glucocorticoids and thyroid hormones on the activities of key enzymes of glycolysis, glutaminolysis, the pentose-phosphate pathway and the Krebs cycle in rat macrophages. J. Endocrinol. 135:213-219.
42. Berg, A.H., Combs, T.P., Du, X., Brownlee, M., and Scherer, P.E. 2001. The adipocyte-secreted protein Acrp30 enhances hepatic insulin action. Nat. Med. 7:947-953.

43. Fruebis, J., et al. 2001. Proteolytic cleavage product of $30-\mathrm{kDa}$ adipocyte complement-related protein increases fatty acid oxidation in muscle and causes weight loss in mice. Proc. Natl. Acad. Sci. U. S. A. 98:2005-2010.

44. Maeda, N., et al. 2002. Diet-induced insulin resistance in mice lacking adiponectin/ACRP30. Nat. Med. 8:731-737.

45. Steppan, C.M., et al. 2001. The hormone resistin links obesity to diabetes. Nature. 409:307-312.

46. Griffin, E., et al. 2001. A link between diabetes and atherosclerosis: Glucose regulates expression of CD36 at the level of translation. Nat. Med. 7:840-846.

47. Sampson, M.J., Davies, I.R., Braschi, S., Ivory, K., and Hughes, D.A. 2003. Increased expression of a scavenger receptor (CD36) in monocytes from subjects with Type 2 diabetes. Atherosclerosis. 167:129-134.

48. Kako, Y., Masse, M., Huang, L.S., Tall, A.R., and Goldberg, I.J. 2002. Lipoprotein lipase deficiency and CETP in streptozotocin-treated apoB-expressing mice. J. Lipid Res. 43:872-877.

49. Reaven, P., Merat, S., Casanada, F., Sutphin, M., and Palinski, W. 1997. Effect of streptozotocin-induced hyperglycemia on lipid profiles, formation of advanced glycation endproducts in lesions, and extent of atherosclerosis in LDL receptor-deficient mice. Arterioscler. Thromb. Vasc. Biol. 17:2250-2256.

50. Febbraio, M., et al. 2000. Targeted disruption of the class B scavenger receptor CD36 protects against atherosclerotic lesion development in mice. J. Clin. Invest. 105:1049-1056.

51. Podrez, E.A., et al. 2002. A novel family of atherogenic oxidized phospholipids promotes macrophage foam cell formation via the scavenger receptor CD36 and is enriched in atherosclerotic lesions. J. Biol. Chem. 277:38517-38523.

52. Linton, M.F., and Fazio, S. 2001. Class A scavenger receptors, macrophages, and atherosclerosis. Curr. Opin. Lipidol. 12:489-495.

53. Koshiyama, H., Shimono, D., Kuwamura, N., Minamikawa, J., and Nakamura, Y. 2001. Inhibitory effect of pioglitazone on carotid arterial wall thickness in type 2 diabetes. J. Clin. Endocrinol. Metab. 86:3452-3456.

54. Ricote, M., Li, A.C., Willson, T.M., Kelly, C.J., and Glass, C.K. 1998. The peroxisome proliferator-activated receptor- $\gamma$ is a negative regulator of macrophage activation. Nature. 391:79-82.

55. Welch, J.S., Ricote, M., Akiyama, T.E., Gonzalez, F.J., and Glass, C.K. 2003. PPAR $\gamma$ and PPAR $\delta$ negatively regulate specific subsets of lipopolysaccharide and IFN- $\gamma$ target genes in macrophages. Proc. Natl. Acad. Sci. U. S. A. 100:6712-6717. 